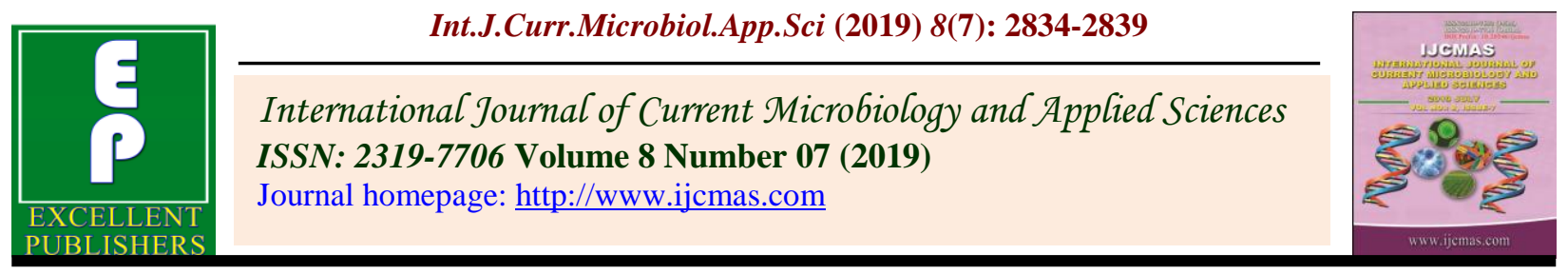

Original Research Article

https://doi.org/10.20546/ijcmas.2019.807.354

\title{
Malaria Transmission Trends with Seasonal Climate Forecast in Different PHCS of YSR District, Andhra Pradesh, India
}

\author{
S. Kusuma Bai*, M. Sasidhar, A. Shashi Kala and B. Naga Sri Latha \\ Department of Microbiology, Govt. Medical College, Kadapa, India \\ *Corresponding author
}

A B S T R A C T

Keywords

Plasmodium vivax,

Plasmodium

falciparum,

Malaria, Male-

female ratio,

Seasonal trends

Article Info

Accepted:

26 June 2019

Available Online:

10 July 2019
Malaria remains a major public health hazard in many low and middle income countries. WHO have endorsed the bold vision of world free of malaria and set the target of reducing the global malaria burden by $90 \%$ by 2030. In India, the epidemiology of malaria is complex because of wide distribution of anopheline vectors which transmit mainly two plasmodial species namely P. falciparum and P. vivax. Though India is one of the known endemic countries, incidence of malaria is commonly influenced by environmental factors like climate, season, temperature and socioeconomic status. Objectives of the study were to know the prevalence of different malarial species and to know the seasonal trend of malaria. The present study reveals the prevalence of malaria in different PHCs of kadapa district of Andhra Pradesh, 2013 to 2018 Incidence (API),

\section{Introduction}

Plasmodium infection continues to cause significant morbidity and mortality for residents and travellers to endemic areas. This protozoan parasite is transmitted through the bite of an Anopheles mosquito and remains an important public health threat. According to the world malaria report there were estimated 219 million cases and 435000 deaths in 2017. Among the nations with $70 \%$ of the world's burden of malaria, only India has managed to reduce its disease burden, registering a $24 \%$ decrease between 2016 and 2017 according to world malaria report 2018
The climatic conditions in India favour the transmission of malaria in remote, rural areas, urban areas, forests, and hills and 20 per cent of population is at high risk of malaria mainly in north-eastern states, Andhra Pradesh, Chhattisgarh, Jharkhand, Madhya Pradesh, Maharashtra, Orissa, Rajasthan, West Bengal and Karnataka. The risk factors leading to complete reconciliation of cause and effect relationships of malaria were identified in India by GIS based studies (Srivastava et al., 1999 \& 2003). In India, 90\% of P. falciparum cases occur in states below the poverty line (Sharma, 2003). Malaria is the most prominent and problematic of all vector borne 
communicable diseases of Andhra Pradesh. Three paradigms of malaria are observed in the state i.e. Tribal, Rural and Urban. Many programmes were implemented for the control of malaria. Many are successful with new Control initiatives as well as promising research initiatives. Even though there is no significant progress in reducing global malaria, its prevalence rose in many parts of the tropics. The Increase in drug resistance of parasites, insecticide resistance of its vectors and human travel and migration have contributed to this resurgence.

According to NVBDCP incidence records, in Andhra Pradesh, annual parasite incidence (API) was 2\%. Persistent malaria is the characteristic feature in most of the areas and both Plasmodium vivax and P. falciparum are prevalent in forest areas of Madhya Pradesh (Singh and Khare, 1999).

Hema Joshi (2003) reported the existence of genetic diversity among the field isolates of $\mathrm{P}$. falciparum and $P$. vivax in India. A hospital based study on assessment of knowledge about malaria among patients indicated that the knowledge about malaria is poor in persons living in urban localities reported with fever (Matta et al., 2004).

Control of malaria is also possible by educating the community to take measures for the non-prevalence of disease (Sharma et al., 2000).

\section{Materials and Methods}

\section{Study area}

The study, was done in the villages of kadapa district which has more PHCs \& CHCs with high population and it contain tropical wet and dry climate which is sufficient for mosquitoes to breed and protozoan to live. We selected 74 PHCs and 10 CHCs to study the prevalence of malaria cases for 6 successive years from 2013 to 2018. In this study we selected who were suffering with fever. They have undergone primary examination and their blood samples were collected by central laboratory.

We used microscopic examination for the diagnosis of malaria by preparing thick and thin smears and stained using field stain. On microscopy we examined for detection of malaria parasite, species identification and different forms of malarial parasites.

\section{Study period}

The data regarding malaria cases from 2013 to 2018 was collected from the Malaria Department of KADAPA district.

\section{Results and Discussion}

The malaria cases were recorded in all the PHCs. In the year 2013, out of 247 cases, 56 were P. falciparum and 191 were $P$. vivax cases. In the year 2014, out of total 407 cases, 87 were P. f. and 320 were P. v. cases. In the year 2015, out of 352 cases, 72 were P. f. and 280 were P. v. cases. In the year 2016, out of 866 cases, 153 were P. f. and 713 were P. v. cases. In the year 2017, out of 521 cases, 47 were P. f. and 474 were P. v. cases. In the year 2018, out of 204 cases, 41 were P. f. and 163 were P. v. Cases. It was also observed that prevalence was more during the months of rainy season (approx. 15\% to 17\%) and was more in males compared to females (male: female ratio $-2: 1$ )

In the present study, it was observed that the highest percentage with regard to malaria cases was found in 2016 from 2013-2018. Malaria prevalence is more especially with $P$. vivax which is due to lack of awareness and preventive measures because the people belong to rural areas. 
A study by Muddaiah et al., demonstrated the highest infection rate of Plasmodium vivax i.e. $52.54 \%$, P. falciparum of $33.75 \%$ and mixed malarial infection rate was $13.69 \%$. In the study of Pakistan by Ali Bin Zubairi S, et al., showed that $P$. vivax and $\mathrm{P}$. falciparum accounted for $83 \%$ and $13 \%$ of cases respectively.

Another Study by Panchal et al., (2016) concluded that high prevalence of $P$. vivax as compared to $P$. falciparum infection. And also reported by Hadiya et al., study where $61.41 \%$ and $38.56 \%$ cases were positive for Plasmodium vivax and $P$. falciparum respectively and comparable seasonal trends with our study. According to Park textbook of Preventive and Social Medicine, In India, about $70 \%$ reported to be due to $P$. vivax, 25$30 \%$ due to P. falciparum, $4-8 \%$ due to mixed infection and $1 \%$ due to P. malaria. We observed $67 \%$ of cases are due to P. vivax and
$33 \%$ of total cases are due to P. falciparum, which correlated with Park textbook of preventive and social medicine.

Males are more frequently exposed to the risk of acquiring malaria. Although malaria affects both men and women gender roles and gender dynamics give rise to different vulnerabilities, such as expose palters (Dept of Gender, women and Health, WHO).

Study of Kumar, et al., showed deaths were more common in men than women across all age groups

In my study it was observed that malaria is a seasonal disease, the maximal prevalence is from July to October. Good rainfall, relative humidity of $60 \%$ and temperature between 20 and $30^{\circ} \mathrm{C}$ favour the spread of malaria (Table 1-2 and Fig. 1-3).

Table.1 Shows Malaria prevalence sex wise ratio

\begin{tabular}{|r|r|r|r|r|r|}
\hline Year & Male & \multicolumn{1}{|c|}{$\boldsymbol{\%}$} & Female & \multicolumn{1}{c|}{ \% } & \multicolumn{1}{c|}{ Total } \\
\hline $\mathbf{2 0 1 3}$ & 169 & 68 & 78 & 32 & 247 \\
\hline $\mathbf{2 0 1 4}$ & 261 & 64 & 146 & 36 & 407 \\
\hline $\mathbf{2 0 1 5}$ & 196 & 55 & 156 & 45 & 352 \\
\hline $\mathbf{2 0 1 6}$ & 714 & 82 & 152 & 18 & 866 \\
\hline $\mathbf{2 0 1 7}$ & 283 & 54 & 238 & 46 & 521 \\
\hline $\mathbf{2 0 1 8}$ & 118 & 57 & 86 & 42 & 204 \\
\hline
\end{tabular}

Table.2 Month wise malaria parasite incidence in Kadapa from 2013 to 2018

\begin{tabular}{|l|l|l|l|l|l|l|l|l|l|l|l|l|l|}
\hline YEAR & JAN & FEB & MAR & APR & MAY & JUNE & JULY & AUG & SEPT & OCT & NOV & DEC & Total \\
\hline $\mathbf{2 0 1 3}$ & 11 & 20 & 20 & 11 & 9 & 17 & 41 & 15 & 12 & 21 & 41 & 29 & 247 \\
\hline $\mathbf{2 0 1 4}$ & 13 & 18 & 10 & 34 & 19 & 32 & 38 & 42 & 72 & 67 & 44 & 18 & 407 \\
\hline $\mathbf{2 0 1 5}$ & 8 & 10 & 9 & 11 & 9 & 44 & 49 & 57 & 54 & 57 & 31 & 13 & 352 \\
\hline $\mathbf{2 0 1 6}$ & 6 & 12 & 21 & 32 & 34 & 47 & 192 & 180 & 160 & 107 & 43 & 32 & 866 \\
\hline $\mathbf{2 0 1 7}$ & 7 & 15 & 22 & 15 & 26 & 11 & 77 & 75 & 64 & 114 & 63 & 32 & 521 \\
\hline $\mathbf{2 0 1 8}$ & 7 & 9 & 21 & 27 & 15 & 23 & 45 & 18 & 9 & 10 & 12 & 8 & 204 \\
\hline Total & 52 & 84 & 103 & 130 & 112 & 174 & 442 & 387 & 371 & 376 & 234 & 132 & 2597 \\
\hline
\end{tabular}


Seasonal variation of malaria from 2013 to 2018

\begin{tabular}{|l|l|l|l|l|}
\hline YEAR & $\begin{array}{l}\text { SUMMER } \\
\text { (Mar-June) }\end{array}$ & $\begin{array}{l}\text { WINTER } \\
\text { (July- Oct) }\end{array}$ & $\begin{array}{l}\text { RAINY } \\
\text { (Nov-Feb) }\end{array}$ & $\begin{array}{l}\text { Total } \\
\text { cases }\end{array}$ \\
\hline $\mathbf{2 0 1 3}$ & 57 & 89 & 101 & 247 \\
\hline $\mathbf{2 0 1 4}$ & 95 & 219 & 93 & 407 \\
\hline $\mathbf{2 0 1 5}$ & 73 & 217 & 62 & 352 \\
\hline $\mathbf{2 0 1 6}$ & 134 & 639 & 93 & 866 \\
\hline $\mathbf{2 0 1 7}$ & 74 & 330 & 117 & 521 \\
\hline $\mathbf{2 0 1 8}$ & 86 & 82 & 36 & 204 \\
\hline Total & 519 & 1576 & 504 & 2597 \\
\hline
\end{tabular}

Fig.1 Prevalence of different types of plasmodium infection

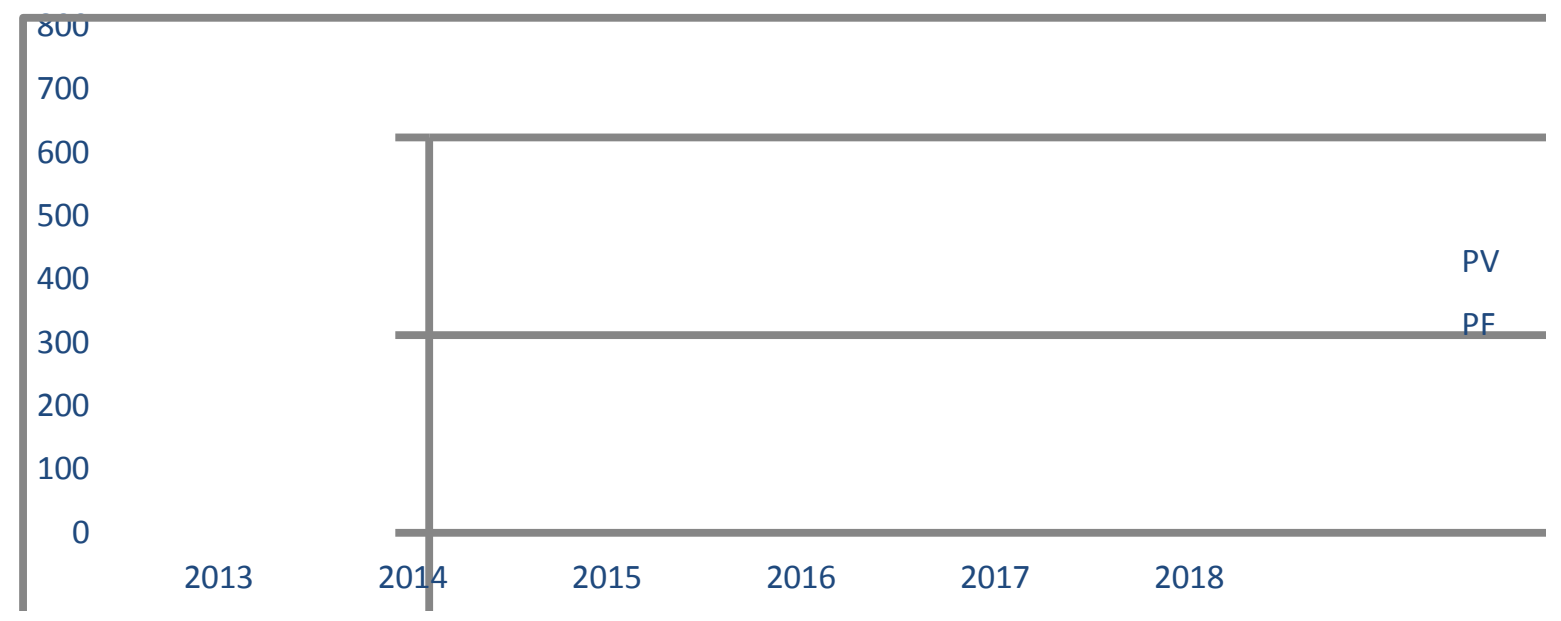

Fig.2 Malaria cases in the focus by sex

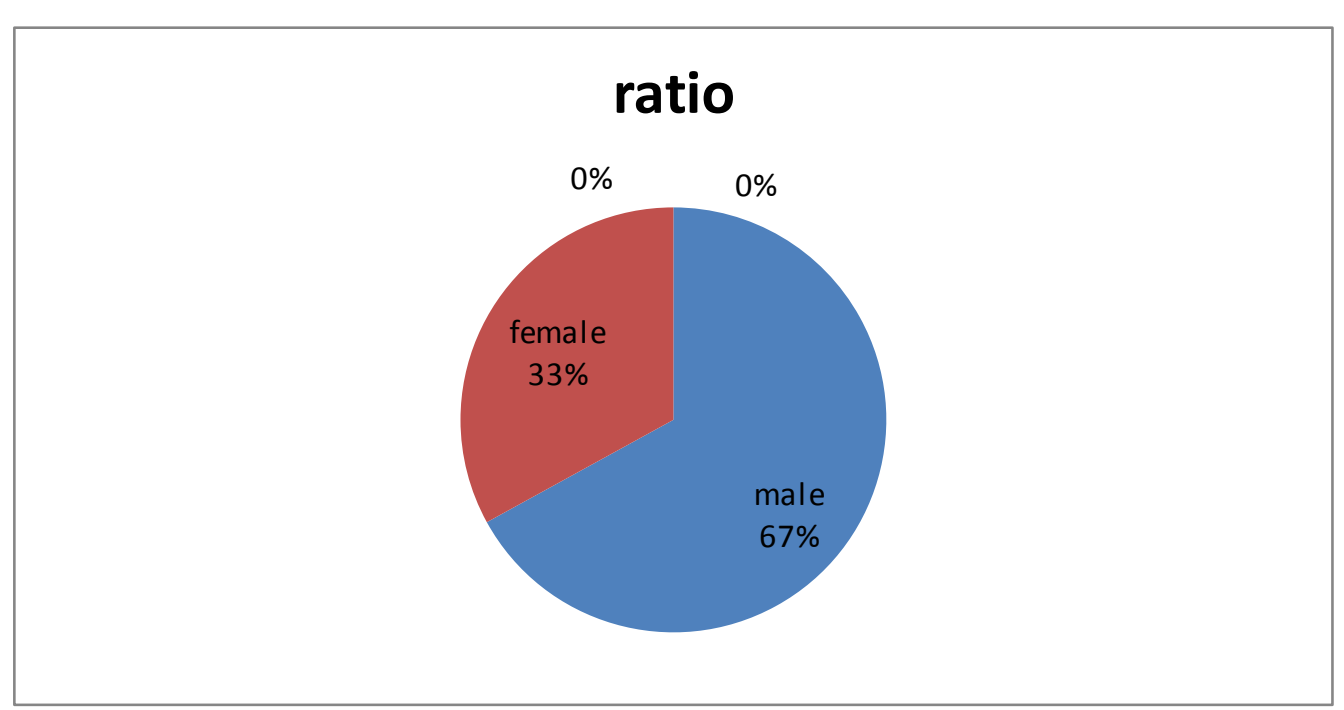


Fig.3 Seasonal variation of malaria

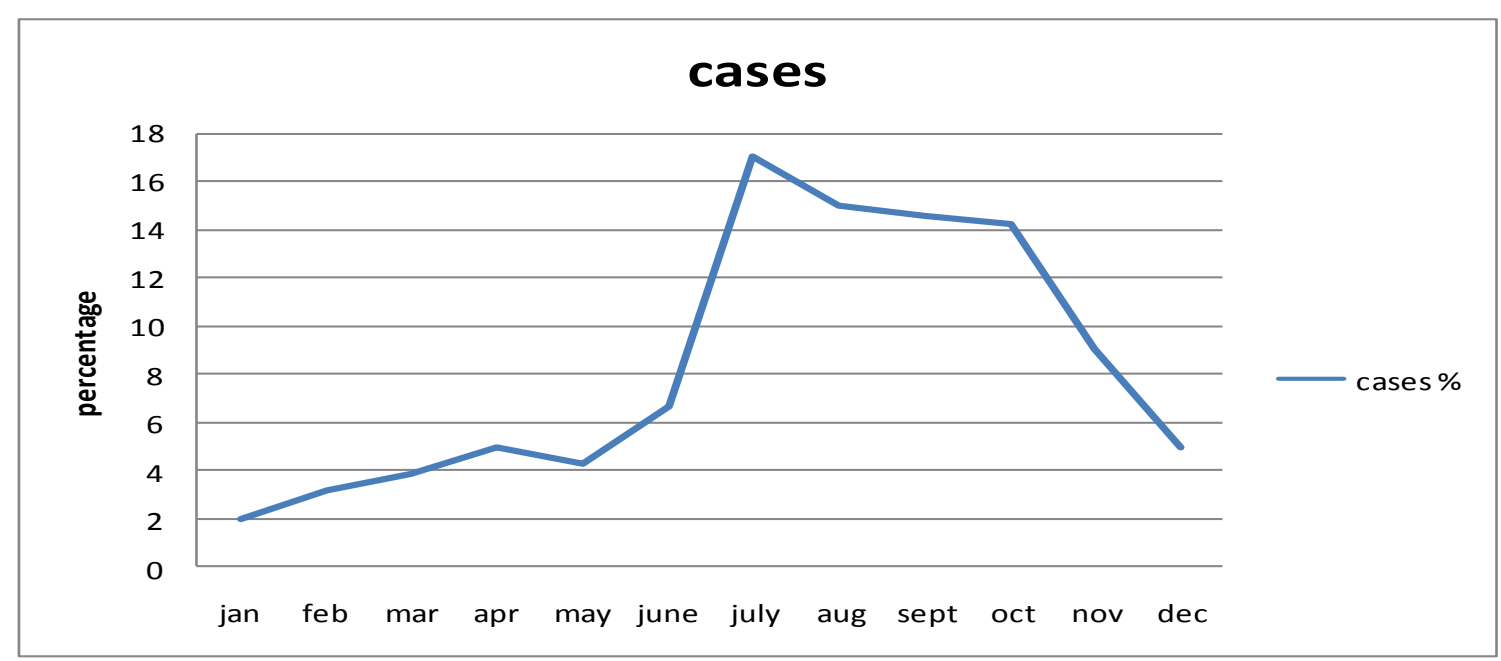

Anjali Singh and Bhagyalaxmi (2010) observed high rate of infection during the monsoon months from July to October and also another study Thomson et al., (2005) and Ayanlade et al., (2010) stated that the seasonality of climate greatly influences the seasonality of malaria transmission

According to Jaydev and Viveka Vardhini, high incidence of malaria cases was reported in august, September, October, November and December 2008 and in January 2009 during the survey period.

Month wise distribution of cases of present study was correlated with study by Prajapati $e t$ al.,

Vashisht et al., (2009) reported the number of malaria positive cases started increasing from

June and reached peak during September 20012006 study.

The department of zoology (2014) study stated that peak transmission was observed during winter season.

From our study, we concluded that there is a high prevalence of $P$. vivax as compare to $\mathrm{P}$. falciparum infection and has also seen more cases in males compared to females and maximum numbers of cases were reported in the month of July to October which concludes that malaria has its peak during the rainy season. There was a substantial reduction in prevalence and incidence rates of both $P$. vivax and P. falciparum thereafter. In order to implement an effective preventive measure, proper surveillance on the incidence and prevalence of malaria is required.

\section{Acknowledgement}

The authors are thankful to the District Malaria Officer and PHC staff members of YSR district, Andhra Pradesh, India

\section{References}

Anjali Singh, A Bhagyalaxmi, (2010). Parasitological observations on seasonality and prevalence of malaria in Ahmedabad district through IDSP. Indian J. Prev. Soc. Med. Vol. 41 No. 3 \& 4. [

Hema Joshi, Markers for population genetic analysis of human plasmodia species, $P$. falciparum and Plasmodium vivax, Journal of Vector Borne Diseases, 40, pp $7883,2003$.

Jayadev, D.J. and V. Viveka vardhani, Incidence of Urban malaria in 
Vijayawada City of Krishna district, Andhra Pradesh, India.

Kumar A, Valecha N, Jain T, Dash AP. Burden of Malaria in India: Retrospective and Prospective View. Am J Trop Med Hyg. 2007; 77 (6): 69-78.

Malaria situation. National Vector Borne Disease control Programme. Available at http://nvbdcp.gov.in/ Doc/ mal_situation_Jan2017

Matta, S., A. Khokhar, and T.R. Sachdev. Assessment of knowledge about malaria among patients reported with fever: A Hospital-Based Study. Journal of Vector Borne Diseases, 41, pp. 27-31, 20

Muddaiah M, Prakash PS. A study of clinical profile of malaria in a tertiary referral centre in South Canara. J Vect Borne Dis. 2006; 43: 29-33.

Panchal PD, Trivedi MB, Shethwala N, Khatri HS. A study of prevalence and seasonal trends of different malarial species in district hospital. Int J Res Med Sci 2016; 4: 4155-7.

Parasitology (Protozoology and Helminthology) by K.D. Chaterjee, 13th edition, Feb 2011, CBS Publishers and Distributors pvt. Itd. Am J Trop Med Hyg, 73, 214 221.

Park K. Text book of preventive and social medicine. XVII edition, November 2015; 193.

Ponnada Srinivasu Department of Zoology, Andhra University, Visakhapatnam, IOSR Journal of Pharmacy and Biological Sciences (IOSR-JPBS) e-ISSN: 22783008, p-ISSN: 2319-7676. Volume 9, Issue 3 Ver. V (May -Jun. 2014), PP 15-
19 www.iosrjournals.org

Prajapati B, A Patel, M Patel. Study of hospital based malaria cases in Mehsana district Of North Gujarat. The Internet Journal of Third World Medicine. 2006; 5(1): 1-6.

Sharma, S.N., N.B.L. Saxena, P.K Phukan, J.K. Anjan, Pandya, A.P. and Shiv Lal. Impact assessment of IEC campaign during antimalaria month June 1998 through KABP study. Journal of Communicable Diseases, 32, pp.49-53, 2000.

Singh, N., and K.K. Khare, Forest Malaria in Madhya Pradesh: Changing scenario of Diseases and its Vectors. Journal of Parasitic Diseases, 23, pp. 105-112, 1999.

Srivastava, A., B.N. Nagpal, R. Saxena and V.P. Sharma. Geographical Information System as a tool to study malaria receptivity in Nadiad Taluka, Kheda District, Gujarat, India.

Thomson, M. C., Connor, S. J., Phindela T., et al., (2005). Rainfall and seasurface temperature monitoring for malaria early warning in Botswana.

Vashisht, B.M., Kalhan Meenakshi, Seema and Jyothi, Situation Analysis of Malaria in District Rohtak, Haryana, Journal of communicable diseases, 41(2), pp. 137138, 2009.

WHO World Malaria Report 2017. WHO, Geneva. Available at http://apps.who.int/ iris/bitstream/10665/144852/2/978924156 4830_eng.pdf

WHO, department of gender, women and health, overview of activities, june 2018

Zubairi ABS. Severe Plasmodium vivax Malaria in Pakistan, Emerging Infectious Diseases. 2011; 19(11): 1851-4.

\section{How to cite this article:}

Kusuma Bai, S., M. Sasidhar, A. Shashi Kala and Naga Sri Latha, B. 2019. Malaria Transmission Trends with Seasonal Climate Forecast in Different PHCS of YSR District, Andhra Pradesh, India. Int.J.Curr.Microbiol.App.Sci. 8(07): 2834-2839. doi: https://doi.org/10.20546/ijcmas.2019.807.354 